\title{
KONDISI IKAN KARANG FAMILI CHAETODONTIDAE DI DAERAH PERLINDUNGAN LAUT DESA BAHOI KECAMATAN LIKUPANG BARAT KABUPATEN MINAHASA UTARA
}

The Condition of Reef Fish Family Chaetodontidae In Marine Protected Areas In Bahoi Village District of West Likupang North Minahasa Regency

\author{
Jacqline Laikun ${ }^{2}$, Ari B. Rondonuwu ${ }^{3}$, Unstain N.W.J. Rembet ${ }^{3}$
}

\begin{abstract}
The coral reefs are a sundry of marine life. Which one is reef fish in family Chaetodontidae. This fish is indicator of the coral reef condition. The aim from the research is : discover of spatial distribution of the reef fish family Chaetodontidae and find out of the intercourse of reef fish family Chaetodontidae with the coral reef presence based on growth of coral form. The research was do in the coral reef at Marine Protected Areas in Bahoi Village District of West Likupang North Minahasa Regency, on Tuesday, December 23rd, 2014. The research is using to do the surveying method. The data is collecting distribution of the fish Chaetodontidae (amount from species and individuals to using by technic visual census). The total of reef fish family Chaetodontidae those found in Marina Protected Areas in Bahoi Village is about 20 species, with total of the individuals at a depth of 3 meters and 10 meters is $\left(56,66\right.$ and 57,33 individuals $\left./ 150 m^{2}\right)$.
\end{abstract}

Keywords : Coral reefs, Chaetodontidae, Bahoi

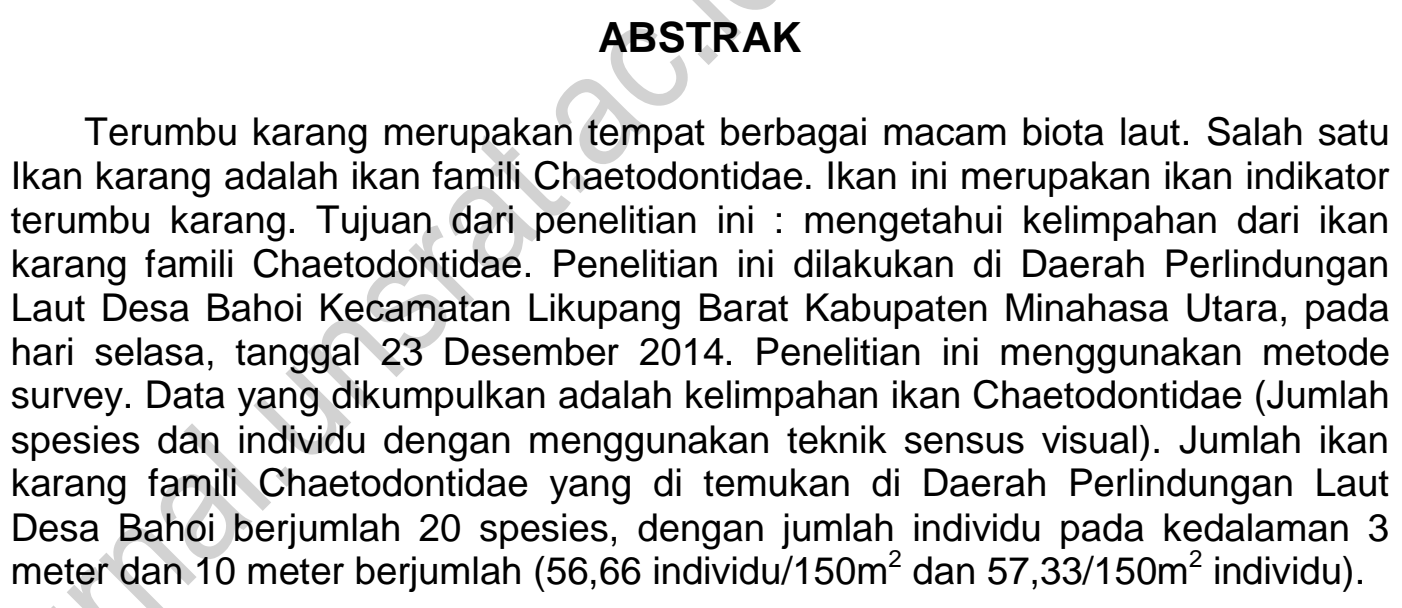

Kata kunci : Terumbu karang, Chaetodontidae, Bahoi

\footnotetext{
${ }^{1}$ Bagian dari skripsi

${ }^{2}$ Mahasiswa Program Studi Manajemen Sumberdaya Perairan FPIK-UNSRAT

${ }^{3}$ Staf pengajar Fakultas Perikanan dan IImu Kelautan Universitas Sam Ratulangi
} 


\section{PENDAHULUAN}

Perairan Indonesia sangat luas dan menyimpan sumberdaya yang cukup besar. Sumberdaya yang melimpah di perairan Indonesia terlebih lagi di Provinsi Sulawesi Utara adalah terumbu karang. Bagi Indonesia terumbu karang merupakan aset yang sangat besar nilainya, selain nilai estetika yang tinggi bagi pariwisata, terumbu karang secara turun-temurun telah dimanfaatkan produktivitasnya oleh penduduk pesisir pantai sebagai lahan pencari ikan (Azkab dan Hutomo, 1998).

Terumbu karang merupakan komunitas yang unik di antara komunitas laut lainnya dan mereka terbentuk seluruhnya dari aktivitas biologi. Pada dasarnya karang merupakan endapan massive kalsium karbonat (kapur) yang diproduksi oleh binatang karang dengan sedkit tambahan dari alga berkapur dan organisme-organisme lain penghasil kalsium karbonat. Klasifikasi ilmiah menunjukkan bahwa karang ini termasuk kelompok binatang dan bukan sebagai kelompok tumbuhan (Sukmara $d k k, 2011$ )

Ikan famili Chaetodontidae adalah salah satu ikan karang penghuni terumbu karang. Kelompok ikan ini disebut ikan kupu-kupu (Butterflyfish) yang dikenal karena memiliki pola warna cemerlang dengan bentuk yang beragam dan variasi ruang spesifik serta gerakan renang yang anggun dan tenang. Ikan ini sering dijadikan ikan hias aquarium laut dan objek penyelam. Ikan-ikan famili Chaetodontidae merupakan spesies indikator karena, memiliki keterkaitan yang erat dengan terumbu karang, karena sebagian besar siklus hidup mereka berlangsung di terumbu karang, serta memiliki keterkaitan dalam hal ketersediaan sumber makanan. Ikan Chaetodontidae dijadikan spesies indikator didasarkan pada preferensi yang kuat terhadap karang batu sebagai komponen utama penyusun terumbu karang.

Daerah Perlindungan Laut Desa

Bahoi adalah salah satu daerah perlindungan laut yang ada di Sulawesi Utara. Daerah perlindungan laut diyakini sebagai salah satu upaya efektif dalam mengurangi kerusakan ekosistem pesisir, yaitu dengan melindungi habitat penting wilayah pesisir, khususnya ekosistem terumbu karang. Perlindungan laut ini dikarenakan terjadinya kerusakan ekosistem terumbu karang, adanya penangkapan ikan menggunakan alat tangkap yang tidak ramah lingkungan atau menggunakan bahan peledak, buangan limbah ke perairan dan untuk mengembalikan ekosistem maupun habitat yang rusak. Hal ini mempengaruhi kelangsungan hidup organisme-organisme perairan seperti ikan Chaetodontidae. Dengan adanya daerah perlindungan laut keberadaan ikan famili Chaetodeontidae tetap terjaga dan dapat meningkatkan keseimbangan ekosistem laut.

Adapun tujuan dari penelitian ini adalah sebagai berikut : Mengetahui kelimpahan dan struktur komunitas ikan famili Chaetodeontidae.

\section{TINJAUAN PUSTAKA}

Ikan karang adalah salah satu biota yang hidup pada ekosistem terumbu karang dan hidupnya sangat tergantung pada kondisi terumbu karang tersebut. Salah satu famili ikan karang yang menjadi indikator kondisi sehat atau tidaknya terumbu karang adalah ikan dari famili Chaetodontidae atau yang mempunyai nama lokal ikan kepekepe, sebagian kecil lainnya merupakan pemakan zooplankton, omnivora, dan invertebrata kecil lainnya.

Ikan Chaetodontidae merupakan kelompok ikthiofauna mencolok memiliki penyebaran luas dan selalu ditemukan hidup berasosiasi dengan terumbu karang, menempatkan famili ini sebagai indikator kondisi karang karena merupakan penghuni karang sejati dan apabila terjadi degradasi terhadap ekosistem terumbu karang, kehadiran ikan ini dapat digunakan sebagai petunjuk 
untuk menilai dan memantau kondisi karang (Marasabessy, 2010).

Kuiter (1992) mencatat famili Chaetodontidae yang telah dikenali dari laut tropik sekitar 120 jenis yang termasuk dalam 10 genus, sedangkan Allen (2003) melaporkan sekitar 114 jenis yang ada diseluruh dunia dan 44 jenis ada di Indonesia. Ikan ini biasanya ditemukan secara individual, berpasangan, atau dalam kelompok kecil.

Sumber makanan menjadi faktor penentu utama yang sistem pertemanan ikan Chaetodontidae. Ikan koralivor umumnya berpasangan dan planktivor berkelompok (Fishbase, 2005 dalam Madduppa, 2006). Ikan Chaetodontidae hidup dekat dengan substrat dan makan secara diurnal. Terdapat lima kategori pemangsaan ikan ini yaitu pemangsa karang batu (hard coral feeder), invertebrata sesil termasuk polip karang (invertebrate sessile feeder), invertebrata bentik, omnivore, dan planktivor (umumnya zooplankton) (Nontji 1993 dan Fishbase 2005 dalam Madduppa, 2006).

\section{METODE PENELITIAN}

Penelitian ini dilakukan di perairan terumbu karang Daerah Perlindungan Laut Desa Bahoi Kecamatan Likupang Barat Kabupaten Minahasa Utara (Gambar 1). Penelitian ini dilakukan di titik koordinat $01.72277^{\circ} \mathrm{N}$ dan $15.02652^{\circ} \quad$ E, $01.72257^{\circ} \mathrm{N}$ dan $125.02498^{\circ} \mathrm{E}$, dan $01.72212^{\circ} \mathrm{N}$ dan $125.02371^{\circ}$. Penelitian dilakukan pada tanggal 23 Desember 2014. Pengambilan data dengan teknik sensus langsung (Sensus Visual Method), pada kedalaman 3 dan 10 meter, dilakukan beberapa menit setelah pemasangan transek garis (panjang transek $30 \mathrm{~m}$ ).

Keanekaragaman jenis (spesies) ikan Chaetodontidae mengikuti Ludwig dan Reynolds (1988). Indeks keanekaragaman yang paling umum digunakan adalah Indeks Shannon yang diterapkan pada komunitas acak dengan ukuran yang besar dimana jumlah total spesies diketahui (Krebs, 1972).

$H^{\prime}=-\sum \frac{n_{i}}{N} \ln \frac{n_{i}}{N}$

Dimana:

$H=$ Indeks keanekaragaman

$N=$ Total jumlah individu

$n_{i}=$ Jumlah individu dalam spesies ke-i

Kriteria penilaian berdasarkan keanekaragaman jenis adalah :

1. $H^{\prime}<1$, keanekaragaman rendah, kestabilan komunitas rendah

2. $1<\mathrm{H}^{\prime}<3$, keanekaragaman sedang, kestabilan komunitas sedang

3. $\mathrm{H}^{\prime}>3$, keanekaragaman tinggi, kestabilan komunitas tinggi

Analisa besaran nilai dominasi ikan Chaetodontidae yang berada di daerah terumbu karang dihitung dengan menggunakan indeks dominasi yang dimodifikasi dari Simpson (Krebs, 1972) sebagai berikut :

$$
C=\sum_{i=1}^{n}\left(\frac{n_{i}}{N}\right)^{2}
$$

Dimana :

$C$ =Indeks dominasi

$N_{i}=$ Jumlah individu ke-i

$N=$ Jumlah total untuk semua spesies

Dengan kisaran nilai indeks dominasi adalah $0-1$, jika nilai mendekati $0 \quad(0-0,50)$ berarti hampir tidak ada spesies atau genera yang mendominasi dan apabila nilai indeks dominasi mendekati $1(0,51-1)$ berarti ada salah satu spesies atau genera yang mendominasi populasi (Krebs, 1972). Kriteria penilaian berdasarkan nilai indeks dominasi adalah :

$$
\begin{aligned}
& 0,00<\mathrm{D} \leq 0,50: \text { Dominasi Rendah } \\
& 0,50<\mathrm{D} \leq 0,75: \text { Dominasi Sedang } \\
& 0,75<\mathrm{D} \leq 1,00: \text { Dominasi Tinggi }
\end{aligned}
$$




\section{HASIL DAN PEMBAHASAN}

Ikan karang famili Chaetodontidae (Butterflyfishes) yang ditemukan berjumlah 20 spesies dari 3 genus yaitu Chaetodon (14 spesies), Heniochus (4 spesies), dan Forcipiger (2 spesies). Jumlah spesies kedalaman 3 meter 17 dan kedalaman 10 meter 16 . Rata-rata jumlah individu pada kedalaman 3 meter $55,67 / 150 \mathrm{~m}^{2}$ dan pada kedalaman 10 meter $57,33 / 150 \mathrm{~m}^{2}$ (Tabel 1).

Pada kedalaman 3 meter jumlah individu Chaetodon kleinii $(18,3 \pm 20,8$ ind $\left./ 150 \mathrm{~m}^{2}\right)$, Heniochus chrysostomus $\left(1,00 \pm 1,00\right.$ ind $\left./ 150 \mathrm{~m}^{2}\right)$, dan Forcipiger flavisimus $\left(4,33 \pm 4,51 \mathrm{ind} / 150 \mathrm{~m}^{2}\right.$ ) (Gambar 2 dan 3). Chaetodon kleinii adalah salah satu spesies dari Chatodontidae yang sangat umum ditemukan di daerah terumbu karang, bahkan pada daerah-daerah yang telah mengalami kerusakan, dikarenakan spesies ini tidak hanya memangsa polip karang, tetapi juga karang lunak, algae, dan zooplankton (Omnivora).

Indeks keanekaragaman spesies pada kedalaman 3 meter dan 10 meter yaitu 2,270 dan 2,003 (Tabel 2 dan Gambar 4). Indeks keanekaragaman ini tergolong Sedang, memiliki kelimpahan spesies yang rendah, dan kestabilan komunitas sedang. Secara umum indeks dominasi di kedalaman 3 meter dan 10 meter adalah 0,163 dan 0,239. Indeks dominasi terendah pada kedalaman 3 meter sedangkan indeks tertinggi pada kedalaman 10 meter, adanya kecenderungan bahwa di kedalaman 10 meter memiliki indeks dominasi lebih besar daripada di kedalaman 3 meter. Semakin kecil indeks dominasi, maka jumlah spesies yang mendominasi wilayah suatu lokasi juga sedikit. Hal ini mengidikasikan bahwa di kedalaman 10 meter memiliki kecenderungan adanya dominasi spesies.

\section{KESIMPULAN}

Berdasarkan penelitian yang dilakukan jumlah koloni komponen penyusun terumbu karang di Daerah Perlindungan Laut Desa Bahoi pada kedalaman 3 meter $(43,67 \mathrm{koloni} / 30 \mathrm{~m})$ dan 10 meter (31,33 koloni/30m). Jumlah spesies dari ikan famili Chaetodontidae berjumlah 20 spesies dari 3 genus yaitu Chaetodon (14 spesies), Heniochus (4 spesies), dan Forcipiger (2 spesies), dimana jenis dengan jumlah individu tertinggi pada kedalaman 3 meter dan 10 meter yaitu Chaetodon kleinii.

\section{DAFTAR PUSTAKA}

Allen G.J., Roger S., Paul H., and Ned D. 2003. Reef Fish Identification Tropical Pasific (16-30). In : New World Publication. Inc. Jacksonville. Florida. USA.

Azkab, M.H dan Hutomo. M(1998). Penyelamatan Terumbu Karang Indonesia: Berpacu Dengan Waktu. Program Rehabilitasi dan Pengelolaan Terumbu Karang (Coremap). 6 hal.

Krebs, C. J. 1972. Ecologi, The Experimental Analisys of Distribution and Abundance. Hapert and Row Publication. New York.

Kuiter, R.H. (1992). Tropical Reef Fishes of The Western Pasific Indonesia and Adjacent Waters. Gramedia Pustaka Utama. Jakarta.

Ludwing, J.A and Reynolds J.F. (1988). Statistical Ecology. A Primer on Methodes and Computing. Jhon Wiley \& Son. Inc. Toronto Canada. 337 hal.

Madduppa, H.H. (2006). Kajian Ekobiologi Ikan Kepe-kepe (Chaetodon octofasciatus, Bloch 1787) Dalam Mendeteksi Kondisi Ekosistem Terumbu Karang Di Pulau Petodon Timur Kepulauan Seribu, Jakarta. Tesis. Sekolah Pascasarna, Institut Pertanian, Bogor. 
Marasabessy, M.D. (2010). Keanekaragaman Jenis Ikan KarangDi Perairan Pesisir Biak, Papua. Junrnal Oseanologi dan Limnologi di Indonesia. Pusat Penelitian Oseanografi-LIPI. 36(1) : 3-84.

Sukmara A., Audrie J.S., dan Christovel R. (2011). Paduan Pemantauan Terumbu Karang BerbasisMasyarakat Dengan Metoda Manta Tow. Proyek Pesisir-CRMP. Publikasi Khusus. University of Rhode Island Coastal Resources Center., Narragansett., Rhode Island,. USA. pp...

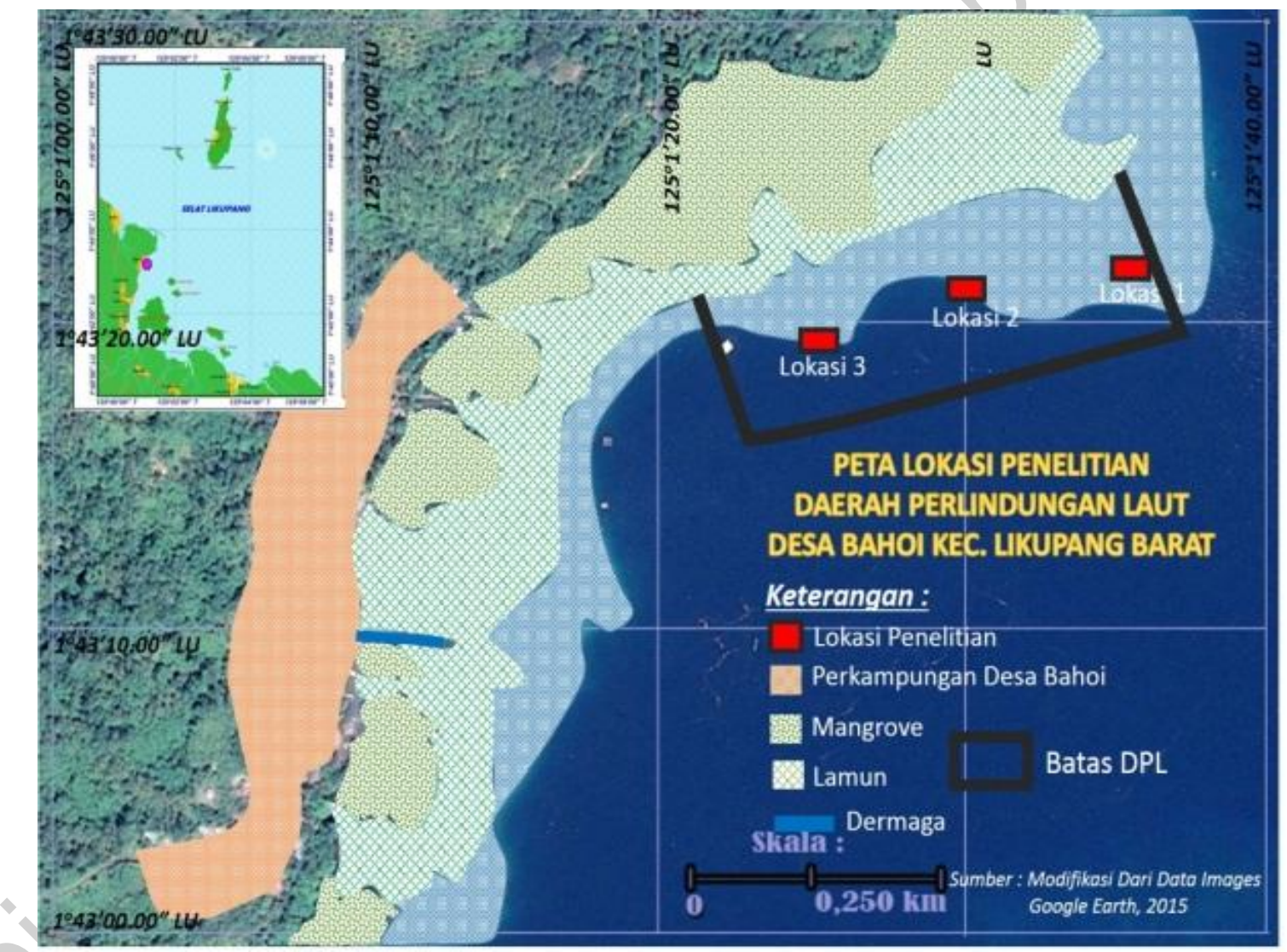

Gambar 1. Peta Lokasi Penelitian 
Tabel 1. Kelimpahan ikan karang famili Chaetodontidae di Daerah Perlindungan Laut Desa Bahoi pada kedalaman 3 dan 10 meter.

\begin{tabular}{|l|l|l|l|l|l|l|}
\hline \multirow{2}{*}{ No } & \multirow{2}{*}{ Spesies } & \multirow{2}{*}{ Kode } & \multicolumn{2}{|c|}{ 3 Meter } & \multicolumn{2}{c|}{ 10 Meter } \\
\cline { 4 - 7 } & & & Rata-rata & SD & Rata-rata & SD \\
\hline 1 & Chaedoton auriga & $\mathrm{Ca}$ & 4,33 & 5,13 & 0,33 & 0,58 \\
\hline 2 & C. baronessa & $\mathrm{Cb}$ & 1,33 & 1,15 & 1,00 & 1,00 \\
\hline 3 & C. citrinellus & $\mathrm{Cc}$ & 1,67 & 1,53 & 3,00 & 5,20 \\
\hline 4 & C. ephippium & $\mathrm{Ce}$ & 2,00 & 3,46 & & \\
\hline 5 & C. klenii & $\mathrm{Ck}$ & 18,3 & 20,8 & 26,00 & 18,20 \\
\hline 6 & C. oxycephallus & $\mathrm{Co}$ & 1,00 & 1,00 & 1,00 & 1,73 \\
\hline 7 & C. ocellicaudus & $\mathrm{Co}$ & 1,33 & 1,15 & 0,67 & 1,15 \\
\hline 8 & C. octofasciatus & $\mathrm{Co}$ & & & 0,67 & 1,15 \\
\hline 9 & C. punctatofasciatus & $\mathrm{Cp}$ & 0,33 & 0,58 & & \\
\hline 10 & C. rafflesi & $\mathrm{Cr}$ & 2,00 & 3,46 & 2,00 & 1,73 \\
\hline 11 & C. speculum & $\mathrm{Cs}$ & 0,33 & 0,58 & & \\
\hline 12 & C. trifascialis & $\mathrm{Ct}$ & 0,67 & 1,15 & 1,33 & 1,15 \\
\hline 13 & C. lunulatus & $\mathrm{Cl}$ & 4,00 & 6,93 & 5,67 & 9,81 \\
\hline 14 & Chaetodon vagabundus & $\mathrm{Cv}$ & 9,33 & 2,08 & 5,00 & 5,57 \\
\hline 15 & Heniochus chrysostomus & $\mathrm{Hc}$ & 1,00 & 1,00 & 2,00 & 3,46 \\
\hline 16 & H. monoceros & $\mathrm{Hm}$ & 0,33 & 0,58 & & \\
\hline 17 & H. singularius & $\mathrm{Hs}$ & & & 0,33 & 0,58 \\
\hline 18 & Heniochus varius & $\mathrm{Hv}$ & 3,33 & 0,58 & 1,33 & 2,31 \\
\hline 19 & Forcipiger flavisimus & $\mathrm{Ff}$ & 4,33 & 4,51 & 4,67 & 4,04 \\
\hline 20 & F. longirostiis & $\mathrm{Fl}$ & & & 2,33 & 4,04 \\
\hline & Jumlah Spesies & & $\mathbf{1 7 , 0 0}$ & & $\mathbf{1 6 , 0 0}$ & \\
\hline & Jumlah Individu & & $\mathbf{5 5 , 6 7}$ & & $\mathbf{5 7 , 3 3}$ & \\
\hline & Indeks keragaman & & $\mathbf{2 , 2 3}$ & & $\mathbf{2 , 0 0}$ & \\
\hline & Indeks dominasi & & $\mathbf{0 , 1 6}$ & & $\mathbf{0 , 2 4}$ & \\
\hline
\end{tabular}
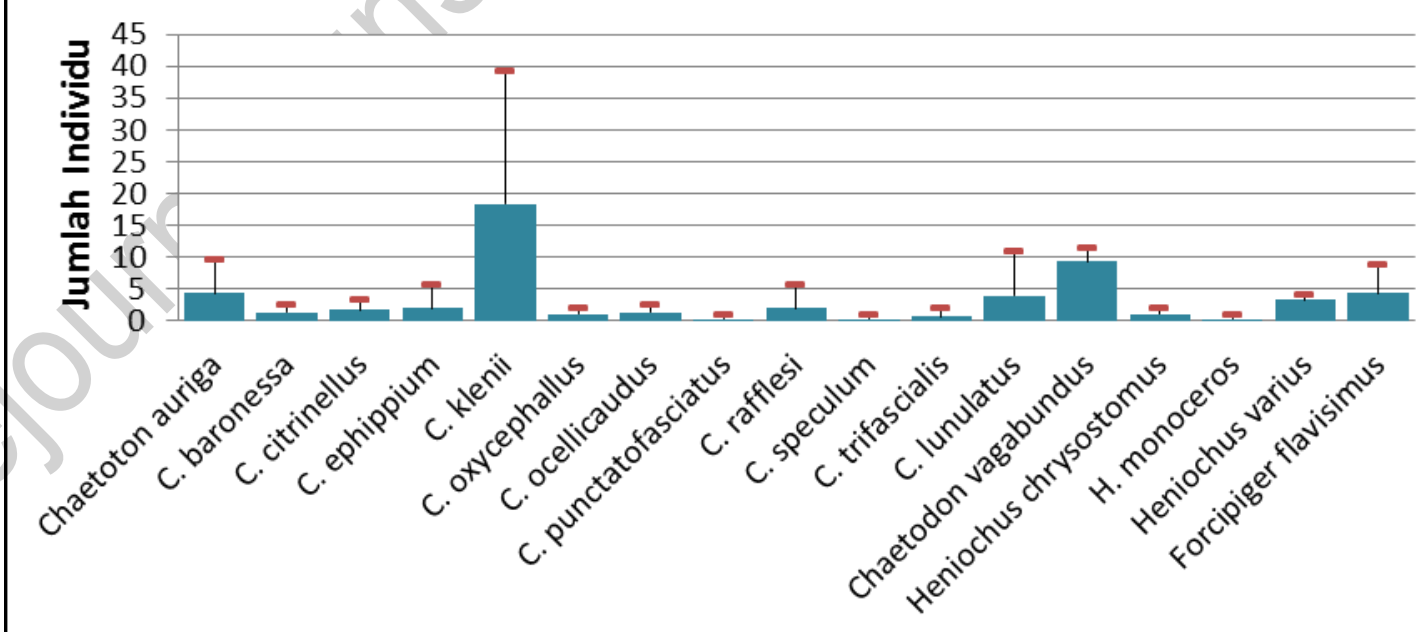

Spesies 
Gambar 2. Kelimpahan ikan Chaetodontidae di Daerah Perlindungan Laut Desa Bahoi di kedalaman 3 meter.

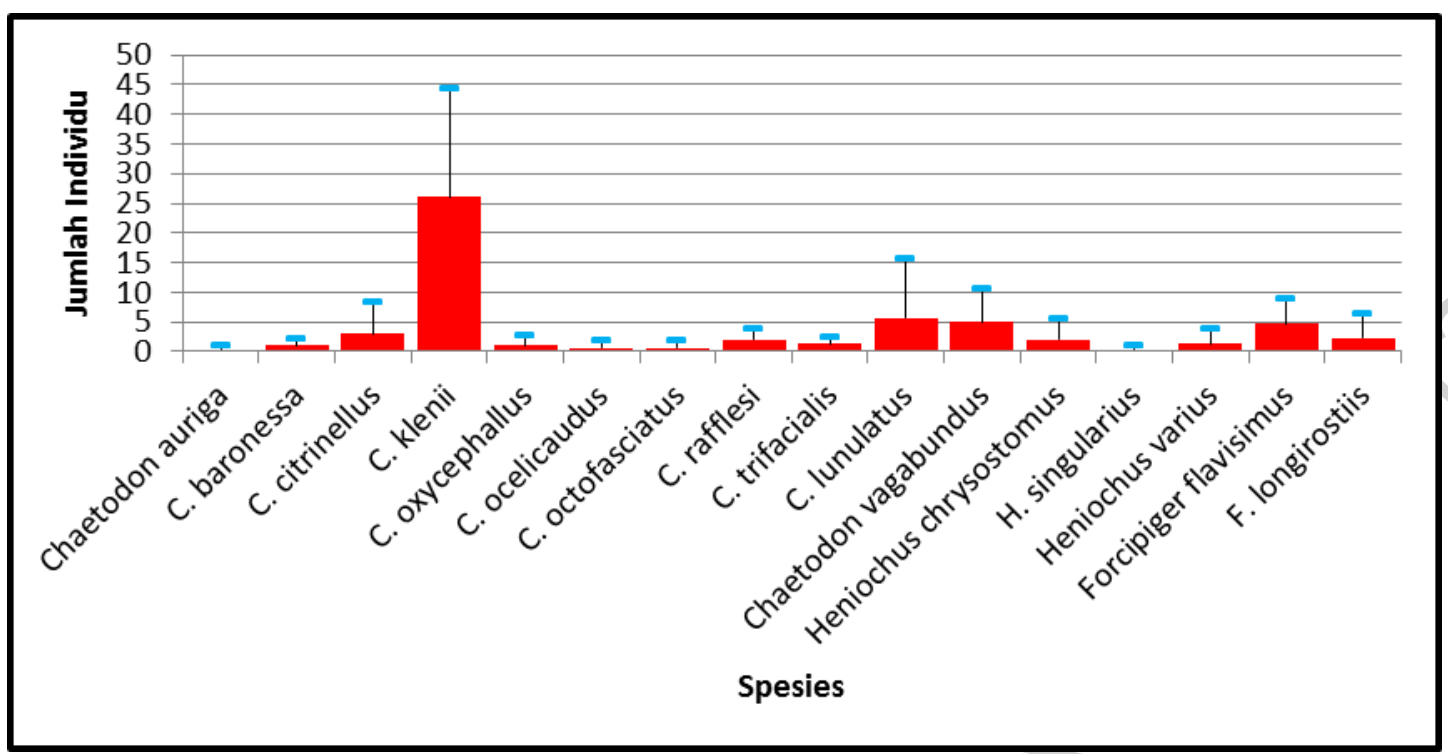

Gambar 3. Kelimpahan ikan Chaetodontidae di Daerah Perlindungan Laut Desa Bahoi di kedalaman 10 meter. 